\title{
Ownership relations in the presence of cross-shareholding
}

\author{
Erik Dietzenbacher · Umed Temurshoev
}

Received: 18 November 2006 / Accepted: 26 March 2008 / Published online: 19 April 2008

(C) The Author(s) 2008

\begin{abstract}
The direct ownership structure in a sector can be readily obtained from data on shareholding. Due to cross-shareholding, however, the true ownership structure may be hidden by a complex network of indirect relations. In studying the property structure, two important aspects are the size of the relations between primary owners (e.g. individuals) and secondary owners (e.g. companies), and the distance between them. The distance is obtained from the average number of secondary owners via whom the relation runs. As an empirical application, we study the banking sector in the Czech Republic, where also the relation between distance and separation of dividend and control rights is discussed.
\end{abstract}

Keywords Cross-shareholding - Ownership relations · Dividend and control rights · Input-output analysis

JEL Classification $\mathrm{L} 16 \cdot \mathrm{G} 32 \cdot \mathrm{D} 57$

\section{Introduction}

The ownership structure of an economy is nowadays often characterized by a complex network of interdependent owners. For example, individual $A$ owns a share in company $B$, who has a share in company $C$. In its turn, $C$ owns a share in $B$. Although $A$ has no direct interest in $C$, there is an indirect relation via $B$. If the operating surplus of $C$

\footnotetext{
E. Dietzenbacher $(\bowtie) \cdot$ U. Temurshoev

Faculty of Economics and Business and SOM Research School,

University of Groningen, PO Box 800, 9700 AV Groningen, The Netherlands

e-mail: H.W.A.Dietzenbacher@rug.nl

U. Temurshoev

e-mail: U.Temurshoev@rug.nl
} 
increases, $A$ benefits through its shares in $B$. If the operating surplus of $B$ increases, $A$ benefits not only directly but also indirectly (for instance, via the gains in $C$ that are beneficial to $B$ again). This is just a very simple case, but it suffices to sketch the setting. Using pure accounting identities, Bolle and Güth (1992) constructed a general model of such interdependent property structures and arrived at the Leontief input-output scheme (see also Turnovec 1999, 2005). In particular, they showed that eliminating all indirect ownership relations results in the final or true distribution of property over the individual owners.

There is a huge body of literature on ownership structures, but only few papers deal with the indirect effects arising from the so called "cross-shareholding" of companies. Due to cross-shareholding, companies have indirect interests in each other. In the literature this structure of ownership and control is also called an "insider system", which is an integral feature of Japanese, German and Swedish business groups in particular (see e.g. Kester 1992). Franks and Mayer (1995) distinguish two types of ownership structures: insider and outsider systems. An insider (or enterprise-oriented) system has a small number of listed companies, an illiquid capital market with infrequent trade of ownership and control, and complex systems of intercorporate holdings. In contrast, an outsider (or market oriented) system is characterized by the existence of a large number of listed companies, a liquid capital market with frequent trade of ownership and control rights, and few intercorporate holdings. In general, it is believed that Continental Europe and Japan have an insider system of ownership structure, while the Anglo-American system is market oriented.

Although indirect interests (such as the one sketched above) have been recognized in the literature (see e.g. Bresnahan and Salop 1986; Reynolds and Snapp 1986; Flath 1989, 1991), only few papers take them into full account by implementing such interests in the models that are used. For example, Ellerman $(1991,1995)$ studies the cross ownership relations between corporations and uses the input-output framework to develop the so called primal and dual theories of ownership and control. His model is particularly relevant for control questions and the proportional representation scheme in voting systems. In a series of papers, Flath (1992a,b, 1993) measures indirect shareholding for six major keiretsu groups in Japan. He shows that indirect shareholding in these groups is large, and should not be neglected because there are gains from indirect shareholding (which might explain the existence of keiretsu groups). Such gains were quantified by Dietzenbacher et al. (2000) in an empirical study for the Dutch financial sector (see also Merlone 2001). The effects of crossshareholding for collusion were studied by Reitman (1994), Alley (1997) and Gilo et al. (2006).

The cross-shareholding of companies may result in a complex network of interdependent relations between economic agents. ${ }^{1}$ Analyzing complexity and relatedness of national production structures, has induced a considerable amount of input-output research (going back to Yan and Ames 1965). In this paper, we want to quantify

\footnotetext{
1 It should be noted that the term "cross-shareholding" as used in the industrial organization literature includes all kinds of ownership relations that are distinguished in the finance literature. These include pyramiding structure, one-sided shareholdings, and mutual (reciprocal) shareholdings (which also includes "ring-form" links).
} 
ownership interrelatedness (and ownership network complexity) in an economy between primary owners (e.g. individuals, the state, municipalities, individuals' nonprofit associations) and secondary owners (e.g. companies, banks, industrial corporations) that is the consequence of cross-shareholding links. In doing so, we take into account not only the size of direct and indirect shareholdings, but also the "average distance" between primary owners and secondary owners. The latter is obtained from the average number of secondary owners via whom such shareholding links between primary owners and secondary owners run.

Taking indirect ownership relations into full account has important theoretical and empirical implications. First, a primary owner may indirectly own a substantial part of some secondary owner, although there may be no direct interest at all. Using the observed property distribution for various purposes (e.g. valuing the property embedded in shares that primary owners hold in secondary owners, assessing decision making power, identifying the role of the state or any other primary owner, finding the distribution of national property or profits) may be quite misleading. In the presence of cross-shareholding, the observed direct ownership distribution may be very different from the true property distribution that incorporates indirect linkages as well.

Second, quantifying indirect ownership relations allows for comparing different sectors in an economy and/or different economies. In some cases, however, qualitative judgments are immediately clear because the shareholding matrices exhibit certain characteristics (such as reducibility).

Third, it would be of interest to link measures of indirect property relations to financial performance indicators. For example, the empirical evidence of the effect of cross-shareholding on corporate performance is ambiguous (see e.g. Prowse 1990; Flath 1993; Lichtenberg and Pushner 1994; Weinstein and Yafeh 1995, 1998; Morck et al. 2000; Yafeh and Yosha 2003). The stable shareholding in Japan, which persisted for almost three decades, began to unwind dramatically in the 1990s. ${ }^{2}$ This raised many fundamental questions about causes, effects and implications of the changes in the Japanese ownership structure. Quantifying ownership relations may shed a new light on the link between ownership structure and corporate performance.

Finally, there is a clear link between our measures of ownership network complexity and the degree of separation of dividend and control rights, widely studied in the finance literature (see e.g. La Porta et al. 1999, 2002; Bebchuk et al. 2000; Claessens et al. 2000; Faccio et al. 2001; Faccio and Lang 2002; Attig and Gadhoum 2003; Gadhoum 2005; Dorofeenko et al. 2008). Cross-shareholding is one of the most important control enhancement devices and our proposed measures of distance take this into full account. We show that, as a consequence, our distance concept can be used as an alternative measure of separation of ownership and control. Ownership relations that are more complex and non-negligible in size may be expected to exhibit a larger gap between dividend and control rights.

\footnotetext{
2 According to Nippon Life Insurance Research Institute (NLIRI) the stable shareholder ratio, defined as the ratio of shares owned by commercial banks, insurance companies, and other non-financial firms (business partners and the parent company) to the total of issued shares of listed firms (calculated on a value basis), was $45 \%$ in the early 1990s, but decreased to $27 \%$ in 2002.
} 
The rest of the paper is organized as follows. Section 2 describes the Leontieftype model of property structure. New measures of ownership network complexity are developed in Sect. 3. The method has been applied to the banking sector of the Czech Republic, the results of which are discussed in Sect. 4. Also in that section, we explore the link to the finance literature, studying the separation of ownership and control. The summary and conclusions are presented in Sect. 5.

\section{Basics of the Leontief-type model of ownership structure}

The main point of departure is the model of property structure, developed by Bolle and Güth (1992) to study a complex network of interdependent owners (see also Turnovec 1999, 2005). Essentially, there are two types of economic agents: principal or primary owners (e.g. individuals, the state, municipalities) and intermediary or secondary owners (e.g. companies, banks, industrial corporations). Principal owners can own intermediary institutions, but cannot be owned themselves. Intermediary institutions can own other intermediary institutions, but are surely owned themselves (by primary and other secondary owners). Due to this cross-shareholding of intermediary owners, principal owners may have no (or little) direct interest in some intermediary owner, but a huge indirect interest (via other secondary institutions).

Suppose there are $m$ primary owners and $n$ secondary owners. The $n \times m$ matrix $\mathbf{P}$ gives the direct primary property distribution. Element $p_{i k}$ indicates the share in company $i(=1, \ldots, n)$ that is held by primary owner $k(=1, \ldots, m)$. The $n \times n$ matrix $\mathbf{S}$ denotes the secondary property distribution. That is, element $s_{i j}$ gives the share in company $i$ that is held by company $j(=1, \ldots, n){ }^{3}$ It is assumed that the shares are all non-negative and that their sum equals one. That is, $\sum_{j} s_{i j}+\sum_{k} p_{i k}=1$ holds for all $i$. In matrix notation we thus have $\mathbf{S} \mathbf{i}_{n}+\mathbf{P} \mathbf{i}_{m}=\mathbf{i}_{n}$, where $\mathbf{i}_{n}$ for example indicates the $n$-dimensional summation vector consisting of ones. This assumption simply states that any secondary owner $i$ is totally owned by principal and other intermediary owners.

$\mathbf{P}$ and $\mathbf{S}$ give the direct property distributions that are actually observed. Eliminating indirect ownership relations results in a total property distribution, which may be significantly different from the observed ownership scheme. The first step in eliminating indirect ownership relations, follows from the observation that primary owner $k$ directly holds a share $p_{i k}$ in company $i$, but it also holds a share $p_{h k}$ in company $h$ which holds a share $s_{i h}$ in $i$ itself. This holds for all $h$, so that primary owner $k$ holds an indirect share in $i$ that amounts to $\sum_{h} s_{i h} p_{h k}$ and which runs via one intermediate owner. The link $k \rightarrow h \rightarrow i$ thus involves two steps, which indicates the "distance" between $k$ and $i$. The "two-step" indirect property distribution is given by the matrix SP. In the same way, primary owner $k$ also holds an indirect share in $i$ via two intermediate owners and thus involving three steps $(k \rightarrow h \rightarrow l \rightarrow i)$. This yields the "three-step" indirect property distribution $\sum_{l} \sum_{h} s_{i l} s_{l h} p_{h k}$, which is element $(i, k)$ of matrix $\mathbf{S}^{2} \mathbf{P}$. And so forth.

\footnotetext{
3 Usually, it is assumed that no secondary owner holds shares in itself, so that the main diagonal of $\mathbf{S}$ is zero. However, as one of the referees rightly noted, this assumption is not always true because due to the tax advantage of capital gains, the share repurchases have recently become the dominant payout policy for corporations. From a mathematical point of view, it is no problem to allow for $s_{i i}>0$.
} 
Taking all such indirect property distributions into consideration (next to the direct initial property structure), gives the total property distribution. It is given by $(\mathbf{I}+\mathbf{S}+$ $\left.\mathbf{S}^{2}+\mathbf{S}^{3}+\cdots\right) \mathbf{P}$, where $\mathbf{I}$ denotes the identity matrix. It is well known that the power series expansion of a non-negative matrix $\mathbf{S}$ equals $(\mathbf{I}-\mathbf{S})^{-1}$, under certain conditions. In the present context, it suffices to assume that for each secondary owner, there is a primary owner that holds a positive share, i.e. matrix $\mathbf{P}$ has some positive element in each row (see e.g. Takayama 1985, for a concise overview of mathematical details). This implies that the total or "true" property distribution is given by the matrix

$$
\mathbf{T}=(\mathbf{I}-\mathbf{S})^{-1} \mathbf{P}
$$

Because $\mathbf{S} \mathbf{i}_{n}+\mathbf{P} \mathbf{i}_{m}=\mathbf{i}_{n}$ implies $(\mathbf{I}-\mathbf{S}) \mathbf{i}_{n}=\mathbf{P} \mathbf{i}_{m}$, we have $\mathbf{i}_{n}=(\mathbf{I}-\mathbf{S})^{-1} \mathbf{P} \mathbf{i}_{m}=\mathbf{T} \mathbf{i}_{m}$. This means that $\mathbf{T}$ satisfies the properties of a distribution. Note that in the end, all property is owned-directly or indirectly — only by principal owners, and all the secondary owners are left with nothing.

The primary property distribution matrix $\mathbf{P}$ with direct shareholding gives the direct ownership relations that are also observed in practice. The indirect relations run via one or more secondary owners and are given by the matrix ${ }^{4}$

$$
\mathbf{Y}=\left(\mathbf{S}+\mathbf{S}^{2}+\mathbf{S}^{3}+\cdots\right) \mathbf{P}=\left[(\mathbf{I}-\mathbf{S})^{-1}-\mathbf{I}\right] \mathbf{P}=\mathbf{T}-\mathbf{P} .
$$

If the value of the secondary owners is known, we can determine the value of the property that is embedded in, for example, a $1 \%$ share in secondary owner $j$. Let $\mathbf{v}^{\prime}$ denote the row vector of the values for the firms (i.e. secondary owners). Then the $j$ th element of the row vector $0.01 \times \mathbf{v}^{\prime}(\mathbf{I}-\mathbf{S})^{-1}$ gives the value embedded in a $1 \%$ share in secondary owner $j$. It is now also possible to evaluate the properties of the primary owners. The $k$ th element of the row vector $\mathbf{v}^{\prime}(\mathbf{I}-\mathbf{S})^{-1} \mathbf{P}=\mathbf{v}^{\prime} \mathbf{T}$ gives the property value of primary owner $k$. Note that the entire property of the secondary owners is distributed over the primary owners, as follows from $\mathbf{v}^{\prime} \mathbf{T} \mathbf{i}_{m}=\mathbf{v}^{\prime} \mathbf{i}_{n}$.

\section{A measure of ownership network complexity}

Given the importance of the indirect relations (or linkages), we will study the complexity of their underlying network. It turns out in the empirical analysis that this allows us to get some insight into the "hidden property structures". As will be clear from the next section, the network complexity measure is a useful indicator of separation of control and ownership rights, since the more complex is the system of non-negligible ownership links, the larger is the control power on firms exerted by primary owners through firms' cross-holdings. Secondly, network complexity measures can be used for comparative analysis. For instance, one economy can be compared with an other in terms of the overall degree of complexity of indirect relations, which identifies the market- or enterprise-orientedness of their ownership structures.

\footnotetext{
$\overline{{ }^{4} \text { An alternative formulation yields } \mathbf{Y}}=\mathbf{S}\left(\mathbf{I}+\mathbf{S}+\mathbf{S}^{2}+\mathbf{S}^{3}+\cdots\right) \mathbf{P}=\mathbf{S}(\mathbf{I}-\mathbf{S})^{-1} \mathbf{P}=\mathbf{S T}$.
} 
The complexity of the indirect ownership relations between principal and intermediary owners is quantified by their weighted average distance. Distance is defined as the number of intermediary owners, via whom the relation runs, plus one. For example if the link between a primary owner $k$ and a secondary owner $i$ runs through secondary owner $h$ (i.e. $k \rightarrow h \rightarrow i$ ), the distance is 2 . It indicates the number of steps that are required to get from $k$ to $i$. The weighted average distance is defined as one plus the average number of participating intermediary owners. In determining the latter average, we use a technique originally developed in the context of input-output models by Harthoorn (1988) and later extended by Dietzenbacher et al. (2005).

Consider the matrix of indirect property relations

$$
\mathbf{Y}=\left(\mathbf{S}+\mathbf{S}^{2}+\mathbf{S}^{3}+\cdots\right) \mathbf{P}=\mathbf{S P}+\mathbf{S}^{2} \mathbf{P}+\mathbf{S}^{3} \mathbf{P}+\cdots
$$

Denote element $(i, k)$ of matrix $\mathbf{S}^{r} \mathbf{P}$ as $\left[\mathbf{S}^{r} \mathbf{P}\right]_{i k}$. In building up the total indirect relation $y_{i k}$, a share $[\mathbf{S P}]_{i k} / y_{i k}$ reflects all relations with distance 2 (i.e. running through exactly one secondary owner). Note that element $(i, k)$ of matrix $\mathbf{S P}$ yields $\sum_{j} s_{i j} p_{j k}$, where the relationship $s_{i j} p_{j k}$ between primary owner $k$ and secondary owner $i$ runs through secondary owner $j$. In the same way, the share $\left[\mathbf{S}^{2} \mathbf{P}\right]_{i k} / y_{i k}$ gives the connections between $k$ and $i$ with distance 3 that run via two secondary owners, because $\sum_{j} \sum_{h} s_{i h} s_{h j} p_{j k}$. In general, the share $\left[\mathbf{S}^{r} \mathbf{P}\right]_{i k} / y_{i k}$ gives all indirect relationships with distance $r+1$ that require $r$ secondary owners.

The weighted average distance between primary owner $k$ and intermediary owner $i$ is given by the weighted average of the distances $r+1$ with weights $\left[\mathbf{S}^{r} \mathbf{P}\right]_{i k} / y_{i k}$ and $r=1,2,3, \ldots$. That is,

$$
\begin{aligned}
& \left(2 \cdot[\mathbf{S P}]_{i k}+3 \cdot\left[\mathbf{S}^{2} \mathbf{P}\right]_{i k}+4 \cdot\left[\mathbf{S}^{3} \mathbf{P}\right]_{i k}+\cdots+(r+1) \cdot\left[\mathbf{S}^{r} \mathbf{P}\right]_{i k}+\cdots\right) / y_{i k} \\
& \quad=\left\{\left(1 \cdot[\mathbf{S P}]_{i k}+2 \cdot\left[\mathbf{S}^{2} \mathbf{P}\right]_{i k}+3 \cdot\left[\mathbf{S}^{3} \mathbf{P}\right]_{i k}+\cdots+r \cdot\left[\mathbf{S}^{r} \mathbf{P}\right]_{i k}+\cdots\right) / y_{i k}\right\}+1
\end{aligned}
$$

The second line of (4) is due to the fact that the shares $\left[\mathbf{S}^{r} \mathbf{P}\right]_{i k} / y_{i k}$ are non-negative and sum to one (i.e. $\sum_{r=1}^{\infty}\left[\mathbf{S}^{r} \mathbf{P}\right]_{i k} / y_{i k}=1$ ). This shows that the weighted average distance equals one plus the weighted average number of intermediary owners involved. The numerator on the right hand side of expression (4) yields $\mathrm{q}_{i j}$, with $\mathbf{Q}=\sum_{r=1}^{\infty} r \mathbf{S}^{r} \mathbf{P}$. Premultiplication by $(\mathbf{I}-\mathbf{S})$ gives

$$
\begin{array}{r}
(\mathbf{I}-\mathbf{S})\left(\sum_{r=1}^{\infty} r \mathbf{S}^{r} \mathbf{P}\right)=\sum_{r=1}^{\infty} r \mathbf{S}^{r} \mathbf{P}-\mathbf{S} \sum_{r=1}^{\infty} r \mathbf{S}^{r} \mathbf{P} \\
=\sum_{r=1}^{\infty} r \mathbf{S}^{r} \mathbf{P}-\sum_{r=1}^{\infty} r \mathbf{S}^{r+1} \mathbf{P}=\sum_{r=1}^{\infty} \mathbf{S}^{r} \mathbf{P}=\mathbf{Y}
\end{array}
$$

using Eq. (3). Hence $(\mathbf{I}-\mathbf{S}) \mathbf{Q}=\mathbf{Y}$ and thus $\mathbf{Q}=(\mathbf{I}-\mathbf{S})^{-1} \mathbf{Y}$. This yields a simple expression for the weighted average number of secondary owners involved as defined in (4). The weighted average distance of the indirect linkages yields $\left(q_{i k} / y_{i k}\right)+1$.

In real world cases, the number of primary and secondary owners may become substantial implying numerous indirect relations. The distance becomes larger and the 
number of paths with the same distance grows rapidly when the number of primary and secondary owners increases. The complexity of this network of indirect relations between primary owner $k$ and secondary owner $i$ is summarized by WADIL $_{i k}=$ $\left(q_{i k} / y_{i k}\right)+1$, the weighted average distance of the indirect linkages (WADIL). A larger distance indicates a more complex network involving a larger number of different paths and is indicated by a larger value of WADIL $_{i k}$.

Several remarks seem to be in place. First, it may happen that WADIL $_{i k}$ cannot be determined, because $y_{i k}=0$. This occurs for example if the matrix $\mathbf{S}$ is reducible. In that case, the secondary owners can be reclassified into two clusters (I and II) and no owner in cluster II holds a share in any of the owners in cluster I. If primary owner $k$ holds only shares in the secondary owners of cluster II, we have that there is no indirect relation between $k$ and secondary owners in cluster I. That is, $y_{i k}=0$ for all $i$ in cluster I. Using partitioned matrices in Eq. (2), and denoting the direct property distribution of primary owner $k$ by the vector $\mathbf{p}$ and the indirect property distribution by the vector $\mathbf{y}$, we have

$$
\left[\mathbf{I}-\left(\begin{array}{cc}
\mathbf{S}_{\mathrm{I}, \mathrm{I}} & 0 \\
\mathbf{S}_{\mathrm{II}, \mathrm{I}} & \mathbf{S}_{\mathrm{II}, \mathrm{II}}
\end{array}\right)\right]^{-1}\left(\begin{array}{c}
0 \\
\mathbf{p}_{\mathrm{II}}
\end{array}\right)-\left(\begin{array}{c}
0 \\
\mathbf{p}_{\mathrm{II}}
\end{array}\right)=\left(\begin{array}{c}
0 \\
\mathbf{y}_{\mathrm{II}}
\end{array}\right)
$$

where, for example, $\mathbf{S}_{\mathrm{II}, \mathrm{I}}$ indicates the shares in a secondary owner in cluster II that are held by a secondary owner in cluster I, $\mathbf{p}_{\mathrm{II}}$ gives the shares in secondary owners in cluster II that are held by primary owner $k$, and $\mathbf{y}_{\mathrm{II}}$ gives the indirect property of secondary owners in cluster II as attributed to primary owner $k$. As a matter of fact, we have $\mathbf{y}_{\mathrm{II}}=\left(\mathbf{I}-\mathbf{S}_{\mathrm{II}, \mathrm{II}}\right)^{-1} \mathbf{p}_{\mathrm{II}}-\mathbf{p}_{\mathrm{II}}$.

Whenever $y_{i k}=0$ we define WADIL $_{i k}=0$, so that the formal definition of the WADIL becomes

$$
\text { WADIL }_{i k}=\left\{\begin{array}{cl}
\left(q_{i k} / y_{i k}\right)+1 & \text { if } y_{i k}>0 \\
0 & \text { if } y_{i k}=0
\end{array}\right.
$$

with $\mathbf{Q}=(\mathbf{I}-\mathbf{S})^{-1} \mathbf{Y}$. Note that whenever an indirect relation exists (i.e. $y_{i k}>0$ ), the number of secondary owners involved in this link cannot be smaller than one. Therefore, also the average number of secondary owners (i.e. $q_{i k} / y_{i k}$ ) cannot be smaller than one and WADIL $i k$ is thus at least two.

Second, if we are interested in the total linkages (i.e. direct plus all indirect linkages) between a primary and a secondary owner, matrix $\mathbf{T}$ can be analyzed in the same way. We have $\mathbf{T}=(\mathbf{I}-\mathbf{S})^{-1} \mathbf{P}=\left(\mathbf{I}+\mathbf{S}+\mathbf{S}^{2}+\cdots+\mathbf{S}^{r}+\cdots\right) \mathbf{P}$ and let $r$ denote the number of secondary owners that act as an intermediate in the total link between primary owner $k$ and secondary owner $i$. Note that this implies that a direct relation between $k$ and $i$ has zero intermediary owners and involves one step. Then, the weighted average distance or number of steps involved is, similar to (4), given by

$$
\begin{aligned}
& \left(p_{i k}+2 \cdot[\mathbf{S P}]_{i k}+3 \cdot\left[\mathbf{S}^{2} \mathbf{P}\right]_{i k}+4 \cdot\left[\mathbf{S}^{3} \mathbf{P}\right]_{i k}+\cdots+(r+1) \cdot\left[\mathbf{S}^{r} \mathbf{P}\right]_{i k}+\cdots\right) / t_{i k} \\
& =\left\{\left(0 \cdot p_{i k}+1 \cdot[\mathbf{S P}]_{i k}+2 \cdot\left[\mathbf{S}^{2} \mathbf{P}\right]_{i k}+3 \cdot\left[\mathbf{S}^{3} \mathbf{P}\right]_{i k}+\cdots+r \cdot\left[\mathbf{S}^{r} \mathbf{P}\right]_{i k}+\cdots\right) / t_{i k}\right\}+1 \\
& =\left(q_{i k} / t_{i k}\right)+1
\end{aligned}
$$


In line with (5), we define the weighted average distance of total linkages (WADTL) as

$$
\text { WADTL }_{i k}= \begin{cases}\left(q_{i k} / t_{i k}\right)+1 & \text { if } t_{i k}>0 \\ 0 & \text { if } t_{i k}=0\end{cases}
$$

Note that if there are neither direct nor indirect linkages we have $t_{i k}=0$ and it makes no sense to examine the average distance. Hence, WADTL $i k=0$ by definition. Also observe that in the case when there is a direct linkage but no indirect linkages, we have that $p_{i k}>0$ and $y_{i k}=0$ imply $q_{i k}=0$ and $t_{i k}>0$, which yields WADTL $i k=1$.

In general, however, there are indirect linkages between $k$ and $i$, implying that $q_{i k} / t_{i k}>0$. Values close to one indicate that the link is essentially of a direct nature, while larger values express that the link is brought about by a complex network of relations. The reason is that (if $p_{i k}>0$ ) generally a large part of the total link is of a direct nature and thus involves only one step (i.e. no intermediary owner). Note that because $\mathbf{Y}=\mathbf{T}-\mathbf{P}$, we have that $\mathrm{WADTL}_{i k}=\left(q_{i k} / t_{i k}\right)+1 \leq\left(q_{i k} / y_{i k}\right)+1=$ WADIL $_{i k}$. That is, the WADTL between $k$ and $i$ is smaller than the WADIL (unless, of course, there are no direct linkages). ${ }^{5}$

\section{An empirical application to the banking sector in the Czech Republic}

For our empirical analysis, we have used the data in Turnovec (1999) for the banking sector in the Czech Republic at the end of $1997 .{ }^{6}$ There are 13 primary owners and 12 secondary owners (see Appendix A for a list, see Turnovec 1999, for further details). The primary property distribution $\mathbf{P}$ and the secondary property distribution $\mathbf{S}$ are given in Appendix B.

\subsection{Analyzing the ownership structure}

For three secondary owners ( $\mathrm{SO}, \mathrm{SO} 8$ and $\mathrm{SO} 12$ ) we observe that their shares are held only by primary owners. Since the corresponding rows in $\mathbf{S}$ contain only zeros, it is not possible to own a part of these secondary owners indirectly (i.e. via one or more secondary owners). This implies that the relation between a primary owner and these three secondary owners can only be direct. The matrix $\mathbf{Y}$ with indirect linkages will thus show only zeros in the corresponding rows. In other words, for these three secondary owners, the primary property distribution in matrix $\mathbf{P}$ tells the whole story. Since there are no indirect linkages, also the matrix with the average distances of the indirect linkages $\left(\mathrm{WADIL}_{i k}\right.$ ) shows rows with only zeros for these secondary owners.

\footnotetext{
5 Absent of direct linkages, all total linkages are indirect. That is, if $p_{i k}=0$ we have $t_{i k}=y_{i k}$ and thus WADTL $_{i k}=$ WADIL $_{i k}$.

6 See e.g. the study by Kenway and Klvacova (1996) on Czech financial institutions, who argue that "cross-ownership is not only a web but also a mask, hiding the extent to which the state remains an owner" (p. 800).
} 
Table 1 Matrix T with total linkages for the banking sector in the Czech Republic (in \%)

\begin{tabular}{lcccccccccccccc}
\hline & PO1 & $P O 2$ & $P O 3$ & $P O 4$ & $P O 5$ & PO6 & PO7 & PO8 & PO9 & PO10 & PO11 & PO12 & PO13 \\
\hline SO1 & 59.23 & 0.38 & 0.28 & 15.04 & 0.32 & 0.06 & 2.15 & 0.37 & 0.09 & 2.33 & 0.25 & 0.37 & 19.11 \\
SO2 & 38.40 & 3.71 & 2.74 & 0 & 3.13 & 0.58 & 20.86 & 0 & 0.86 & 0 & 0 & 3.61 & 26.11 \\
SO3 & 50.90 & 0.03 & 0.02 & 0.23 & 0.02 & 0.00 & 0.14 & 13.01 & 0.01 & 0.04 & 0.00 & 0.02 & 35.58 \\
SO4 & 31.49 & 0 & 0 & 0 & 18.20 & 3.36 & 0 & 0 & 5.02 & 0 & 0 & 0 & 41.93 \\
SO5 & 19.59 & 26.51 & 19.59 & 0 & 0 & 0 & 0 & 0 & 0 & 0 & 0 & 25.78 & 8.53 \\
SO6 & 14.84 & 0.10 & 0.07 & 3.77 & 0.08 & 0.01 & 0.54 & 0.09 & 0.02 & 30.58 & 0.06 & 0.09 & 49.74 \\
SO7 & 14.80 & 0.10 & 0.07 & 3.76 & 0.08 & 0.01 & 0.54 & 0.09 & 0.02 & 30.58 & 10.06 & 0.09 & 39.79 \\
SO8 & 0 & 0 & 0 & 0 & 0 & 0 & 100 & 0 & 0 & 0 & 0 & 0 & 0 \\
SO9 & 5.30 & 0.51 & 0.38 & 0 & 0.43 & 0.08 & 2.88 & 0 & 0.12 & 0 & 0 & 0.50 & 89.80 \\
SO10 & 24.25 & 0.37 & 0.28 & 0 & 0.32 & 0.06 & 2.11 & 0 & 0.09 & 0 & 0 & 0.36 & 72.17 \\
SO11 & 14.77 & 0.01 & 0.01 & 0.07 & 0.01 & 0.00 & 0.04 & 3.77 & 0.00 & 0.01 & 0.00 & 0.01 & 81.31 \\
SO12 & 0 & 0 & 0 & 0 & 41.1 & 42.7 & 0 & 0 & 0 & 0 & 0 & 0 & 16.20 \\
\hline
\end{tabular}

Very small numbers close to zero are denoted by 0.00

The matrices $\mathbf{T}$ and $\mathbf{Y}$ with the sizes of total and indirect shares in secondary owners held by primary owners are given in Tables 1 and 2, respectively. Because all the shares that are held by secondary owners are now accrued to primary owners, the matrix $\mathbf{Y}$ has more positive elements than the matrix $\mathbf{P}$. In analyzing this matrix $\mathbf{Y}$, let us focus first on the zero elements. Next to the rows for SO5, SO8 and SO12 (which contain only zeros, as has been explained above), we observe that also the row for $\mathrm{SO} 4$ contains primarily zeros. Note that $\mathrm{SO} 4$ is owned by four primary owners (PO1, $P O 5, P O 9, P O 13$ ) and one secondary owner (SO12). In its turn, however, all shares in this secondary owner are held by primary owners $P O 5, P O 6$, and $P O 13$. Therefore, PO5, PO6, and PO13 are the only primary owners that have an indirect link to SO4, so that $y_{4 k}=$ WADIL $_{4 k}=0$ for $k \neq 5,6,13$. Note that the indirect link between, for example, PO5 and SO4 runs only through SO12. We have $y_{45}=s_{4,12} \times p_{12,5}=$ $0.0786 \times 0.4110=0.0323$. SO12 being the only intermediary owner also explains why WADIL $45=$ WADIL $_{46}=$ WADIL $_{4,13}=2$ in Table 3 (which gives the matrix with the WADILs). $P O 1$ and PO9 have a direct link to SO4 (i.e. $p_{41}, p_{49}>0$ ), but not an indirect link.

Additional zeros in Tables 2 and 3 are found for the linkages between primary owners PO4, PO8, PO10 and PO11, and secondary owners SO2, SO9 and SO10. It turns out that each of these primary owners, only holds shares in (and thus has a direct link to) one or more secondary owners in the cluster SO1, SO3, SO6, SO7, SO11. In addition, each of these secondary owners only holds shares in one or more other members of the cluster. So, the indirect linkages only involve members of the cluster and it is thus impossible to achieve a link between one of the four primary owners (PO4, PO8, PO10 and PO11) and a secondary owner other than SO1, SO3, SO6, SO7, $S O 11$. This implies that all remaining entries (i.e. in rows $2,4,5,8,9,10,12$ ) are zero in the columns 4, 8,10 and 11 . 
Table 2 Matrix $\mathbf{Y}$ with indirect linkages for the banking sector in the Czech Republic (in \%)

\begin{tabular}{lcllllllllllll}
\hline & $P O 1$ & $P O 2$ & $P O 3$ & $P O 4$ & $P O 5$ & $P O 6$ & $P O 7$ & $P O 8$ & $P O 9$ & $P O 10$ & $P O 11$ & $P O 12$ & $P O 13$ \\
\hline$S O 1$ & 6.43 & 0.38 & 0.28 & 0.29 & 0.32 & 0.06 & 2.15 & 0.37 & 0.09 & 2.33 & 0.25 & 0.37 & 7.16 \\
$S O 2$ & 8.15 & 3.71 & 2.74 & 0 & 3.13 & 0.58 & 20.86 & 0 & 0.86 & 0 & 0 & 3.61 & 8.40 \\
$S O 3$ & 2.16 & 0.03 & 0.02 & 0.23 & 0.02 & 0.00 & 0.14 & 0.09 & 0.01 & 0.04 & 0.00 & 0.02 & 5.75 \\
$S O 4$ & 0 & 0 & 0 & 0 & 3.23 & 3.36 & 0 & 0 & 0 & 0 & 0 & 0 & 1.27 \\
$S O 5$ & 0 & 0 & 0 & 0 & 0 & 0 & 0 & 0 & 0 & 0 & 0 & 0 & 0 \\
$S O 6$ & 14.84 & 0.10 & 0.07 & 3.77 & 0.08 & 0.01 & 0.54 & 0.09 & 0.02 & 0.58 & 0.06 & 0.09 & 4.79 \\
$S O 7$ & 14.80 & 0.10 & 0.07 & 3.76 & 0.08 & 0.01 & 0.54 & 0.09 & 0.02 & 0.58 & 0.06 & 0.09 & 4.78 \\
$S O 8$ & 0 & 0 & 0 & 0 & 0 & 0 & 0 & 0 & 0 & 0 & 0 & 0 & 0 \\
$S O 9$ & 5.30 & 0.51 & 0.38 & 0 & 0.43 & 0.08 & 2.88 & 0 & 0.12 & 0 & 0 & 0.50 & 3.60 \\
$S O 10$ & 3.88 & 0.37 & 0.28 & 0 & 0.32 & 0.06 & 2.11 & 0 & 0.09 & 0 & 0 & 0.36 & 2.64 \\
$S O 11$ & 14.77 & 0.01 & 0.01 & 0.07 & 0.01 & 0.00 & 0.04 & 3.77 & 0.00 & 0.01 & 0.00 & 0.01 & 10.32 \\
$S O 12$ & 0 & 0 & 0 & 0 & 0 & 0 & 0 & 0 & 0 & 0 & 0 & 0 & 0 \\
\hline
\end{tabular}

Very small numbers close to zero are denoted by 0.00

Table 3 Weighted average distances of indirect linkages $\left(\mathrm{WADIL}_{i k}\right)$ for the banking sector in the Czech Republic

\begin{tabular}{lllllllllllllll}
\hline & $P O 1$ & $P O 2$ & $P O 3$ & $P O 4$ & $P O 5$ & $P O 6$ & $P O 7$ & PO8 & PO9 & PO10 & PO11 & PO12 & PO13 \\
\hline SO1 & 2.341 & 3.043 & 3.043 & 3.040 & 3.220 & 4.043 & 3.043 & 2.053 & 3.043 & 2.040 & 2.040 & 3.043 & 2.220 \\
SO2 & 2 & 2 & 2 & 0 & 2.177 & 3 & 2 & 0 & 2 & 0 & 0 & 2 & 2.026 \\
SO3 & 2.334 & 4.023 & 4.023 & 2.053 & 4.200 & 5.023 & 4.023 & 3.016 & 4.023 & 3.053 & 3.053 & 4.023 & 2.102 \\
SO4 & 0 & 0 & 0 & 0 & 2 & 2 & 0 & 0 & 0 & 0 & 0 & 0 & 2 \\
SO5 & 0 & 0 & 0 & 0 & 0 & 0 & 0 & 0 & 0 & 0 & 0 & 0 & 0 \\
SO6 & 2.146 & 4.043 & 4.043 & 2.040 & 4.220 & 5.043 & 4.043 & 3.053 & 4.043 & 3.040 & 3.040 & 4.043 & 2.457 \\
SO7 & 2.146 & 4.043 & 4.043 & 2.040 & 4.220 & 5.043 & 4.043 & 3.053 & 4.043 & 3.040 & 3.040 & 4.043 & 2.457 \\
SO8 & 0 & 0 & 0 & 0 & 0 & 0 & 0 & 0 & 0 & 0 & 0 & 0 & 0 \\
SO9 & 2.212 & 3 & 3 & 0 & 3.177 & 4 & 3 & 0 & 3 & 0 & 0 & 3 & 2.330 \\
SO10 & 2.212 & 3 & 3 & 0 & 3.177 & 4 & 3 & 0 & 3 & 0 & 0 & 3 & 2.330 \\
SO11 & 2.057 & 5.023 & 5.023 & 3.053 & 5.200 & 6.023 & 5.023 & 2.014 & 5.023 & 4.053 & 4.053 & 5.023 & 2.178 \\
SO12 & 0 & 0 & 0 & 0 & 0 & 0 & 0 & 0 & 0 & 0 & 0 & 0 & 0 \\
\hline
\end{tabular}

Another interesting issue is the case where some primary owner $k$ has no direct link to a certain secondary owner $i$ (i.e. $p_{i k}=0$ ), but substantial indirect linkages (i.e. $y_{i k}>0$ ). In this case, the information in the actually observed matrix $\mathbf{P}$ does not at all reflect the true ownership structure. For example, $P O 7$ has no direct share in $S O 2$, but indirectly it owns more than $20 \%$ of the property of SO2. Similarly, about $15 \%$ of the property of SO6, SO7 and $\mathrm{SO} 11$ is indirectly held by $\mathrm{PO} 1$ although there is no direct interest in them. The same applies to the majority of primary and secondary owners' relations, but to a much lesser extent. Tables 2 and 3 also show that the presence of a direct interest does not necessarily mean that there is an indirect link as well. For instance, $y_{41}=$ WADIL $_{41}=0$, although $p_{41}>0$. 


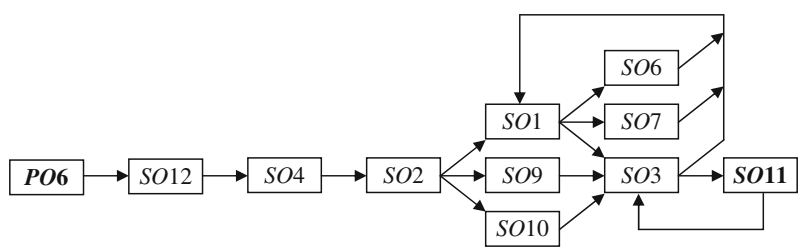

Fig. 1 Indirect connection between PO6 and SO11 for the banking sector in the Czech Republic

Note that in Table 3 we have used two types of numbers. Integer numbers (i.e. without any decimals) are exact. For example, WADIL W $_{i k}=3$ indicates that all indirect connections between primary owner $k$ and secondary owner $i$ involve always exactly three steps (i.e. two intermediary owners). Using the initial property distribution in $\mathbf{P}$, we see that e.g. WADIL $93=$ WADIL $_{10,3}=3$ are both brought about through the intermediation of $\mathrm{SO} 5$ and $\mathrm{SO}$. An exceptional case is underlying $\mathrm{WADIL}_{21}=2$. All indirect linkages between $\mathrm{PO} 1$ and $\mathrm{SO} 2$ involve exactly two steps, but there are two of such paths. One runs via SO4 and the other via SO5. Outcomes that are not given as an integer reflect that there are at least multiple paths of different lengths.

Closer inspection of the numbers in Tables 2 and 3 suggests that there is an inverse relationship between WADIL $_{i k}$ and the size $y_{i k}$ of the indirect shareholdings. This should not be too much of a surprise as follows from Eq. (4). A "large" value of WADIL $_{i k}$ (say, 5 or so) indicates that the weight $\left[\mathbf{S}^{r} \mathbf{P}\right]_{i k} / y_{i k}$ must be reasonably large for values $r=4,5$, and 6 , for example. Thus $\left[\mathbf{S}^{4} \mathbf{P}\right]_{i k},\left[\mathbf{S}^{5} \mathbf{P}\right]_{i k}$, and $\left[\mathbf{S}^{6} \mathbf{P}\right]_{i k}$ have a considerable contribution to $y_{i k}$. In general, however, $\left[\mathbf{S}^{r} \mathbf{P}\right]_{i k}$ declines rapidly when $r$ increases. This explains why in many cases "large" values of WADIL $i k$ are found for values $y_{i k}$ close to zero. The correlation coefficient between size and weighted average distance is -0.534 for the indirect linkages (based on the 95 cases with $y_{i k}>0$ ). Hence, smaller average distances are associated, to some extent, with larger indirect shares.

Table 3 shows that WADIL $_{11,6}=6.023$ is the largest, i.e. PO6 owns shares of SO11 through 5.023 secondary owners on average. Using the primary and secondary property distributions in Appendix B, this connection is graphed in Fig. 1. The graph shows that the "shortest" connection between PO6 and SO11 can be established through three paths, each involving six steps (via five secondary owners: $\mathrm{SO} 12 \rightarrow \mathrm{SO} 4 \rightarrow \mathrm{SO} 2 \rightarrow \mathrm{SO} 1 \rightarrow \mathrm{SO} 3 ; \mathrm{SO} 12 \rightarrow \mathrm{SO} 4 \rightarrow \mathrm{SO} \rightarrow \mathrm{SO} \rightarrow \mathrm{SO} 3 ;$ and $\mathrm{SO} 12 \rightarrow$ $\mathrm{SO} 4 \rightarrow \mathrm{SO} 2 \rightarrow \mathrm{SO} 10 \rightarrow \mathrm{SO} 3$ ). Because of mutual shareholdings (between the cluster SO6, SO7, SO3 on the one hand and SO1 on the other hand, and between SO3 and SO11) there is in fact an infinite number of paths through which PO6 indirectly owns property of $S O 11$. It should be stressed, however, that the property attributed to $P O 6$ through paths involving eight or more steps is practically zero. Figure 1 also graphs the connections of $P O 6$ with any other secondary owner. For example, PO6 owns $0.58 \%$ of $S O 2$ via exactly two intermediary owners (i.e. three steps), thus we have $y_{26}=0.58$ and $\mathrm{WADIL}_{26}=3$.

So far we have discussed the WADIL, which is of particular interest to detect the interests that cannot be seen straightforwardly from the observed data. One might be more interested in the total linkages between a principal and a secondary owner, no matter whether they are direct or indirect. The total linkages are obtained from the 
Table 4 Weighted average distances of total linkages $\left(\mathrm{WADTL}_{i k}\right.$ ) for the banking sector in the Czech Republic

\begin{tabular}{lllllllllllllll}
\hline & $P O 1$ & $P O 2$ & $P O 3$ & $P O 4$ & $P O 5$ & $P O 6$ & $P O 7$ & $P O 8$ & $P O 9$ & PO10 & PO11 & PO12 & PO13 \\
\hline SO1 & 1.146 & 3.043 & 3.043 & 1.040 & 3.220 & 4.043 & 3.043 & 2.053 & 3.043 & 2.040 & 2.040 & 3.043 & 1.457 \\
SO2 & 1.212 & 2 & 2 & 0 & 2.177 & 3 & 2 & 0 & 2 & 0 & 0 & 2 & 1.330 \\
SO3 & 1.057 & 4.023 & 4.023 & 2.053 & 4.200 & 5.023 & 4.023 & 1.014 & 4.023 & 3.053 & 3.053 & 4.023 & 1.178 \\
SO4 & 1 & 0 & 0 & 0 & 1.178 & 2 & 0 & 0 & 1 & 0 & 0 & 0 & 1.030 \\
SO5 & 1 & 1 & 1 & 0 & 0 & 0 & 0 & 0 & 0 & 0 & 0 & 1 & 1 \\
SO6 & 2.146 & 4.043 & 4.043 & 2.040 & 4.220 & 5.043 & 4.043 & 3.053 & 4.043 & 1.039 & 3.040 & 4.043 & 1.140 \\
SO7 & 2.146 & 4.043 & 4.043 & 2.040 & 4.220 & 5.043 & 4.043 & 3.053 & 4.043 & 1.039 & 1.013 & 4.043 & 1.175 \\
SO8 & 0 & 0 & 0 & 0 & 0 & 0 & 1 & 0 & 0 & 0 & 0 & 0 & 0 \\
SO9 & 2.212 & 3 & 3 & 0 & 3.177 & 4 & 3 & 0 & 3 & 0 & 0 & 3 & 1.053 \\
SO10 & 1.194 & 3 & 3 & 0 & 3.177 & 4 & 3 & 0 & 3 & 0 & 0 & 3 & 1.049 \\
SO11 & 2.057 & 5.023 & 5.023 & 3.053 & 5.200 & 6.023 & 5.023 & 2.014 & 5.023 & 4.053 & 4.053 & 5.023 & 1.150 \\
SO12 & 0 & 0 & 0 & 0 & 1 & 1 & 0 & 0 & 0 & 0 & 0 & 0 & 1 \\
\hline
\end{tabular}

matrix $\mathbf{T}=\mathbf{P}+\mathbf{Y}$. The number of intermediary owners involved in any specific link is given by $\mathrm{WADTL}_{i k}=\left(q_{i k} / t_{i k}\right)+1$, expressing the weighted average distance of total linkages between primary owner $k$ and secondary owner $i$. The results are given in Table 4. Note that WADTL $i k=0$ if $t_{i k}=0$ which indicates that there is no link, neither directly nor indirectly. The cases where $t_{i k} \neq 0$ and $q_{i k}=0$ yield WADTL $_{i k}=1$ and reflect that there is a direct link but no indirect link. This implies that any cell for which WADIL $_{i k}=0$ in Table 3 , shows a 0 or a 1 in Table 4 . No indirect linkages (i.e. WADIL ${ }_{i k}=0$ ) means that there are only direct linkages (i.e. WADTL $_{i k}=1$ ) or no linkages at all (i.e. WADTL $i k=0$ ).

Comparing the non-zero elements in Table 3 with their corresponding elements in Table 4 , shows that $0<$ WADTL $_{i k}<$ WADIL $_{i k}$ if and only if there is a direct link between $k$ and $i$ (i.e. $p_{i k}>0$ ). ${ }^{7}$ In most cases, the average distance falls substantially once direct links are taken into account, because the direct linkage is a large part of the total linkage. Hence, values of $\mathrm{WADTL}_{i k}$ that are close to one indicate that the link is mainly direct. As was the case with $\mathrm{WADIL}_{i k}$, large values hint at the existence of a complex network of relations that underlie a certain link.

One application of the proposed indirect measures is that they can be used for comparative analyses. For example, the banking sector could be compared with another sector, or the banking sector could be compared for different years, or the banking sector in one country could be compared with that in another country. The overall degree of complexity of the network of indirect relations is reflected by the overall average of the weighted average distances (based on indirect or total linkages). In our empirical application, this average of the weighted average distances is 1.949 for the indirect linkages and 1.861 for the total linkages. The first indicator is the simple

\footnotetext{
7 WADIL $_{i k}>0$ implies $y_{i k}>0$ and thus $q_{i k}>0$ (because $\mathbf{Q} \geq \mathbf{Y}$ ). Then $t_{i k}>y_{i k}$ if and only if $p_{i k}>0$, and using the definitions in (5) and (6) straightforwardly proves the equivalence.
} 
average of all the WADILs and the second of the WADTLs. Recall that WADIL W $_{i k}=0$ if there is no indirect linkage between $k$ and $i$, and WADIL $i k \geq 2$ otherwise. Similarly, we have that WADTL $_{i k}=0$ if there is no linkage between $k$ and $i$, WADTL $_{i k}=1$ if there is only a direct link, and WADTL $_{i k}>1$ if there is an indirect link. ${ }^{8}$ Thus, the results for the overall average distance indicate that shareholding linkages in the Czech banking sector are brought about by a complex network of relations, and that they cannot be associated with linkages of a direct nature only.

\subsection{Ownership network complexity and separation of dividend and control rights}

An important issue in the finance literature is the separation of control and dividend rights due to pyramiding structure and cross-holdings (see e.g., La Porta et al. 1999, 2002; Bebchuk et al. 2000; Claessens et al. 2000; Faccio et al. 2001; Faccio and Lang 2002; Attig and Gadhoum 2003; Gadhoum 2005; Dorofeenko et al. 2008). One of the main findings in these studies is that control (or voting) rights in the presence of cross-holdings, pyramiding structures, and dual class shares usually exceed dividend (or cash-flow) rights. Control rights are obtained from the so called "weakest link" approach used in all studies cited above, except Dorofeenko et al. (2008) who propose the "dominant shareholder" methodology for this purpose. In this subsection we will argue that our measure of property network complexity may be used as an alternative.

As a very brief introduction to cash-flow and control rights, consider the following simple hypothetical cases of a pyramidal structure:

$$
\begin{aligned}
& \text { Family } a: 50 \% \text { in firm } \alpha \rightarrow 11 \% \text { in } \beta \rightarrow 11 \% \text { in } \gamma \rightarrow 10 \% \text { in } \delta \rightarrow 11 \% \text { in } \varepsilon \\
& \text { Family } b: 10 \% \text { in } \varepsilon
\end{aligned}
$$

The percentages represent the shares held in the "next" firm. For example, family $a$ holds $50 \%$ of the shares in firm $\alpha$, which holds $11 \%$ of the shares in firm $\beta$, etcetera. The question is what the cash flow (O) and control (C) rights of each family are in the last firm $\varepsilon$.

Clearly, family $b$ owns $10 \%$ of both $\mathrm{O}$ and $\mathrm{C}$ rights in $\varepsilon$, if we assume that there are no dual-class shares (i.e., under the one-share-one-vote rule). For family $a$, the ownership stake is equal to the product of all cash-flow rights along the property chain. Hence, family $a$ owns only $0.50 \times 0.11 \times 0.11 \times 0.10 \times 0.11 \approx 0.007 \%$ of the $\mathrm{O}$ stake in firm $\varepsilon$. According to the "weakest link" methodology, the C stake of family $a$ is equal to the minimum of the control stakes in the ownership chain. Hence, the

\footnotetext{
${ }^{8}$ It should be emphasized that the WADILs (WADTLs) that are zero are included in calculating the overall average indirect (total) linkages. Neglecting the zero-elements would give us the average of the weighted average distances for the cases in which an indirect linkage exists. As an overall measure for comparative purposes, however, this would have a clear drawback that is sketched by the following example. Consider a sector with many secondary owners but no cross-shareholding except for a mutual interest between say $S O 1$ and $S O 2$. The overall average distance could well be substantial if the zero-elements were not taken into consideration, whereas the network of indirect relations is extremely simple. Taking all WADILs into account would in this example yield a very low overall average, in line with the simplicity of the structure. So, in determining the overall complexity of a network, it is important to take all possible connections into consideration.
} 
family has $10 \% \mathrm{C}$ rights in $\varepsilon$, provided that the threshold level is not larger than $10 \% .^{9}$ For family $a$, the separation of ownership and control thus is huge $(\mathrm{O} \approx 0.007 \%$ and $\mathrm{C}=10 \%$ ). According to the "weakest link" approach, both families have the same control power in $\varepsilon$, although there is a large difference in their $O$ stakes.

One might argue that it is more reasonable that the direct control of $10 \%$ for family $b$ is much larger in terms of real power than the indirect control of $10 \%$ via four intermediate firms in case of family $a$. It thus seems that the "weakest link" approach misses such incongruencies between $\mathrm{O}$ and $\mathrm{C}$ rights, which occur in the presence of cross-ownership relations among firms. Precisely these relations are fully captured by our notion of distance.

Following the above line of reasoning, one might expect that countries with the largest (smallest) separation of ownership and control have a more (less) complex network of ownership relations. Consequently, one would expect the proposed distance measures to be large (small). Claessens et al. (2000), Faccio and Lang (2002), Attig and Gadhoum (2003) and Gadhoum (2005) report the following O/C ratios (in ascending order). Japan: 0.602; Switzerland: 0.740; Italy: 0.743; Indonesia: 0.784; Singapore: 0.794; Germany: 0.842: Canada: 0.850; Philippines: 0.908; Portugal: 0.924; France: 0.930; USA: 0.940; Thailand: 0.941; and Spain: 0.941. Some average O/C ratios are Canada-USA: 0.895; Western Europe: 0.868; and East Asia: 0.746. These results are in line with the reciprocal relationship between complexity and the $\mathrm{O} / \mathrm{C}$ ratio. In East Asia and Japan in particular, firms are historically interlinked through strong shareholding interlocks, yielding complex ownership structures. This suggests that our notion of distance can be considered as an alternative measure of separation of ownership and control, fully taking into account means of enhancing control such as non-pyramidal cross-ownerships (both one-sided and reciprocal). ${ }^{10}$

Also Dorofeenko et al. (2008) observe that "for more complicated cross-ownership the product of shares and the minimum share along the chain are insufficient statistics for ownership and control, respectively". This implies that the "weakest link" approach is suitable only for pyramidal cross-ownership relations, where the chains of ownership stakes are easily tractable. Hence, for non-pyramidal cross-ownership relations more general measures for $\mathrm{O}$ and $\mathrm{C}$ rights are required. They suggest to trace a controlling primary owner for each firm, and propose the methodology that rests on construction of control assignments on the base of "dominant shareholder" theorem that identifies controllers according to relative majority of (both direct and indirect) voting shares. Shortly, their approach is as follows. The $n \times m$ matrix $\mathbf{C}$ gives the control coefficients. Its typical element $c_{i k}$ is an indicator function that takes a positive value if company $i(=1, \ldots, n)$ is controlled by primary owner $k(=1, \ldots, m)$, and zero otherwise. Then the share of votes in company $i$ by some primary owner $k$ is given by $p_{i k}+\sum_{j} s_{i j} c_{j k}$,

\footnotetext{
9 It should be mentioned that usually only control stakes that exceed certain threshold levels (typically 10 and $20 \%$ ) are considered.

10 It should be noted that dual-class shares are not covered by our approach. At the same time, multiple class shares are not the most common equity structure. According to Bebchuk et al. (2000), the reason is that "the corporate law of some jurisdictions restricts both the voting ratio between high- and low-ratio shares and the numerical ratio between high- and low-vote shares that a firm is permitted to issue". The studies mentioned above, report that only 19.91, 16.10, and 8.19\% of firms in, respectively, Europe, Canada, and the US issue multiple class equity as a mean to enhance control.
} 
Table 5 Control rights according to the "weakest link" approach (without threshold) for the Czech banking sector (in \%)

\begin{tabular}{lccccccccccccc}
\hline & $P O 1$ & $P O 2$ & $P O 3$ & $P O 4$ & $P O 5$ & $P O 6$ & $P O 7$ & $P O 8$ & $P O 9$ & $P O 10$ & $P O 11$ & $P O 12$ & $P O 13$ \\
\hline$S O 1$ & 65.70 & 12.90 & 12.90 & 14.75 & 12.90 & 10.66 & 12.90 & 2.80 & 7.82 & 7.60 & 2.50 & 12.90 & 24.85 \\
$S O 2$ & 61.43 & 14.00 & 14.00 & 0 & 17.18 & 7.86 & 20.86 & 0 & 5.02 & 0 & 0 & 14.00 & 43.42 \\
$S O 3$ & 55.04 & 6.30 & 6.30 & 1.53 & 6.30 & 6.30 & 6.30 & 12.92 & 6.30 & 1.53 & 1.53 & 6.30 & 36.13 \\
$S O 4$ & 31.49 & 0 & 0 & 0 & 22.81 & 7.86 & 0 & 0 & 5.02 & 0 & 0 & 0 & 48.52 \\
$S O 5$ & 19.59 & 26.51 & 19.59 & 0 & 0 & 0 & 0 & 0 & 0 & 0 & 0 & 25.78 & 8.53 \\
$S O 6$ & 25.05 & 12.90 & 12.90 & 14.75 & 12.90 & 10.66 & 12.90 & 2.80 & 7.82 & 32.50 & 2.50 & 12.90 & 69.80 \\
$S O 7$ & 24.99 & 12.90 & 12.90 & 14.75 & 12.90 & 10.66 & 12.90 & 2.80 & 7.82 & 35.10 & 10.00 & 12.90 & 59.86 \\
$S O 8$ & 0 & 0 & 0 & 0 & 0 & 0 & 100 & 0 & 0 & 0 & 0 & 0 & 0 \\
$S O 9$ & 13.80 & 13.80 & 13.80 & 0 & 13.80 & 7.86 & 13.80 & 0 & 5.02 & 0 & 0 & 13.80 & 100 \\
$S O 10$ & 30.47 & 10.10 & 10.10 & 0 & 10.10 & 7.86 & 10.10 & 0 & 5.02 & 0 & 0 & 10.10 & 79.63 \\
$S O 11$ & 29.01 & 6.30 & 6.30 & 1.53 & 6.30 & 6.30 & 6.30 & 12.92 & 6.30 & 1.53 & 1.53 & 6.30 & 100 \\
$S O 12$ & 0 & 0 & 0 & 0 & 41.10 & 42.70 & 0 & 0 & 0 & 0 & 0 & 0 & 16.20 \\
\hline
\end{tabular}

which in matrix form yields $\mathbf{P}+\mathbf{S C}$. After this reassignment of shares, the remaining "uncontrolled" voting shares reduce to $\mathbf{S}\left(\mathbf{I}-\operatorname{diag}\left(\mathbf{C} \mathbf{i}_{m}\right)\right)$, where $\operatorname{diag}\left(\mathbf{C} \mathbf{i}_{m}\right)$ is the $n \times n$ diagonal matrix with the row sums of $\mathbf{C}$ along its diagonal. The authors show that relative majority, unlike absolute majority as the criterion relevant for control, ensures that every firm is controlled only by primary owner(s), because a largest shareholder always exists. Thus the last matrix of "uncontrolled" shares is a zero matrix implying that $\mathbf{C} \mathbf{i}_{m}=\mathbf{i}_{n} .{ }^{11}$ So the control rights are given by the matrix $\mathbf{P}+\mathbf{S C}$, which also add to one for each firm $i$, i.e. $(\mathbf{P}+\mathbf{S C}) \mathbf{i}_{m}=\mathbf{i}_{n}$.

In the remainder of this subsection, we compare our WADTL and WADIL measures with the "weakest link" and "dominant shareholder" approaches, applied to the Czech banking sector. Control rights of primary owners according to the "weakest link" methodology are given in Table 5, where for the moment we do not impose any threshold level on their sizes (hence, the row sums are all bigger than one except for SO5, SO8, and SO12). To illustrate, we examine the derivation of control rights for the case of $P O 6$, which is also graphically illustrated in Fig. 2.

All possible shareholding links among secondary owners are illustrated in Fig. 2. Assuming the one-share-one-vote rule, first, it is easy to see that PO6 has $42.70 \%$ control and cash flow stakes in SO12. The minimum stake in the ownership chain until SO4 is 7.86\%, which is thus the control stake of PO6 in SO4. By the same logic, PO6 owns $7.86 \%$ of control rights in SO2, SO9, and SO10. To find the control stake in $S O 3$, consider the three ownership chains that pass through SO1, SO9 and SO10, respectively. Then the corresponding control share is equal to the sum of the minimum stakes along these three chains is $6.30 \%(=1.53+1.21+3.56 \%)$ gives the control

\footnotetext{
11 The control coefficients satisfy the following two conditions. (1) If $c_{i k}>0$, then $p_{i k}+\sum_{j} s_{i j} c_{j k} \geq$ $p_{i l}+\sum_{j} s_{i j} c_{j l}$ for all $l=1, \ldots, m$, for all $k=1, \ldots, m$, and all $i, j=1, \ldots, n$; and (2) $\sum_{k=1}^{m} c_{i k}=1$ for all $i=1, \ldots, n$. See Dorofeenko et al. (2008) for further details.
} 
Fig. 2 Identification of control rights of $P O 6$ according to the "weakest link" methodology (without threshold).

Note: S stands for the size of shareholding between secondary owners, C- control rights of $P O 6$ in corresponding company

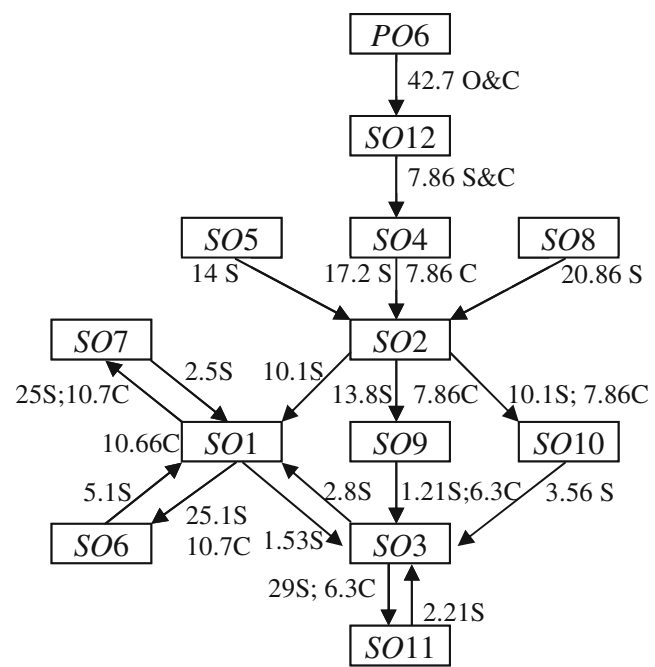

rights of $P O 6$ in SO3. Similarly, the control stake of PO6 in SO1 equals $10.66 \%$, the sum of the minimum stakes in the links via SO2 and SO3 $(=7.86+2.80 \%)$. Notice that the mutual cross-holdings of SO1 with SO6 and of SO1 with SO7 have been disregarded. The reason is that we would consider such mutual links only if $S O 1$ owned at least $50 \%$ of SO6 and SO7, which in turn own SO $1 .{ }^{12}$ Since the control stake of $10.66 \%$ in SO1 is smaller than the ownership stakes of the SO1 in SO6 and SO7, we have that PO6 owns $10.66 \%$ of the control rights in SO6 and SO7 as well. Finally, the control stake of PO6 in SO11 is $6.30 \%$, equal to that in SO3 and smaller than the direct stake of SO3 in SO11 (i.e., 29.01\%).

Because our dataset is fairly small, the matrix of control coefficients on the basis of relative majority of votes is easily found. The underlying intuition is thoroughly explained in Dorofeenko et al. (2008). For a small dataset the control coefficients can be derived iteratively as follows. First, take the $n \times m$ matrix $\mathbf{C}^{(0)}$ that has unity in all cells that correspond to positive cells in the matrix $\mathbf{P}$, and zeroes elsewhere. Next, from the secondary property distribution matrix $\mathbf{S}$, the firms are found that are not owned by any other secondary owner. In our case, these are SO5, SO8, and SO12. Because these firms cannot be owned indirectly, we search in the corresponding rows of $\mathbf{P}$ for the shareholder(s) with the largest stake. These are assigned a positive value in the corresponding cell(s) of $\mathbf{C}^{(0)}$, and the remaining elements become zero. If there is more than one shareholder with the same (largest) stake, they receive equal control coefficients, such that the sum of coefficients equals one. From $\mathbf{P}$ in Appendix B, it follows that $c_{5,2}^{(0)}=1, c_{8,7}^{(0)}=1, c_{12,6}^{(0)}=1$, and $c_{i k}^{(0)}=0$ for $i=5,8$, and 12 , and all other $k$ 's in these rows. Now, in the second stage we compute $\mathbf{P}+\mathbf{S C}^{(0)}$, find from the matrix $\mathbf{S}$ firms that are owned only by one other secondary owner, and for these

\footnotetext{
12 If this would have been the case, we would have added 5.1 and $2.5 \%$ to the $10.66 \%$ of $P O 6$ control rights in $S O 1$.
} 
Table 6 The control assignment matrix for the banking sector in the Czech Republic

\begin{tabular}{llllllllllllll}
\hline & $P O 1$ & $P O 2$ & $P O 3$ & $P O 4$ & $P O 5$ & $P O 6$ & $P O 7$ & $P O 8$ & $P O 9$ & $P O 10$ & $P O 11$ & $P O 12$ & $P O 13$ \\
\hline$S O 1$ & 1 & 0 & 0 & 0 & 0 & 0 & 0 & 0 & 0 & 0 & 0 & 0 & 0 \\
$S O 2$ & 0 & 0 & 0 & 0 & 0 & 0 & 0 & 0 & 0 & 0 & 0 & 0 & 1 \\
$S O 3$ & 1 & 0 & 0 & 0 & 0 & 0 & 0 & 0 & 0 & 0 & 0 & 0 & 0 \\
$S O 4$ & 0 & 0 & 0 & 0 & 0 & 0 & 0 & 0 & 0 & 0 & 0 & 0 & 1 \\
$S O 5$ & 0 & 1 & 0 & 0 & 0 & 0 & 0 & 0 & 0 & 0 & 0 & 0 & 0 \\
$S O 6$ & 0 & 0 & 0 & 0 & 0 & 0 & 0 & 0 & 0 & 0 & 0 & 0 & 1 \\
$S O 7$ & 0 & 0 & 0 & 0 & 0 & 0 & 0 & 0 & 0 & 0 & 0 & 0 & 1 \\
$S O 8$ & 0 & 0 & 0 & 0 & 0 & 0 & 1 & 0 & 0 & 0 & 0 & 0 & 0 \\
$S O 9$ & 0 & 0 & 0 & 0 & 0 & 0 & 0 & 0 & 0 & 0 & 0 & 0 & 1 \\
$S O 10$ & 0 & 0 & 0 & 0 & 0 & 0 & 0 & 0 & 0 & 0 & 0 & 0 & 1 \\
$S O 11$ & 0 & 0 & 0 & 0 & 0 & 0 & 0 & 0 & 0 & 0 & 0 & 0 & 1 \\
$S O 12$ & 0 & 0 & 0 & 0 & 0 & 1 & 0 & 0 & 0 & 0 & 0 & 0 & 0 \\
\hline
\end{tabular}

Table 7 Control rights according to the "dominant shareholder" approach for the Czech banking sector (in \%)

\begin{tabular}{lccccccccccccc}
\hline & $P O 1$ & $P O 2$ & $P O 3$ & $P O 4$ & $P O 5$ & $P O 6$ & $P O 7$ & $P O 8$ & $P O 9$ & $P O 10$ & $P O 11$ & $P O 12$ & $P O 13$ \\
\hline$S O 1$ & 55.60 & 0 & 0 & 14.75 & 0 & 0 & 0 & 0 & 0 & 0 & 0 & 0 & 29.65 \\
$S O 2$ & 30.25 & 14.00 & 0 & 0 & 0 & 0 & 20.86 & 0 & 0 & 0 & 0 & 0 & 34.89 \\
$S O 3$ & 50.27 & 0 & 0 & 0 & 0 & 0 & 0 & 12.92 & 0 & 0 & 0 & 0 & 36.81 \\
$S O 4$ & 31.49 & 0 & 0 & 0 & 14.97 & 7.86 & 0 & 0 & 5.02 & 0 & 0 & 0 & 40.66 \\
$S O 5$ & 19.59 & 26.51 & 19.59 & 0 & 0 & 0 & 0 & 0 & 0 & 0 & 0 & 25.78 & 8.53 \\
$S O 6$ & 25.05 & 0 & 0 & 0 & 0 & 0 & 0 & 0 & 0 & 30 & 0 & 0 & 44.95 \\
$S O 7$ & 24.99 & 0 & 0 & 0 & 0 & 0 & 0 & 0 & 0 & 30 & 10 & 0 & 35.01 \\
$S O 8$ & 0 & 0 & 0 & 0 & 0 & 0 & 100 & 0 & 0 & 0 & 0 & 0 & 0 \\
$S O 9$ & 0 & 0 & 0 & 0 & 0 & 0 & 0 & 0 & 0 & 0 & 0 & 0 & 100 \\
$S O 10$ & 20.37 & 0 & 0 & 0 & 0 & 0 & 0 & 0 & 0 & 0 & 0 & 0 & 79.63 \\
$S O 11$ & 29.01 & 0 & 0 & 0 & 0 & 0 & 0 & 0 & 0 & 0 & 0 & 0 & 70.99 \\
$S O 12$ & 0 & 0 & 0 & 0 & 41.10 & 42.7 & 0 & 0 & 0 & 0 & 0 & 0 & 16.2 \\
\hline
\end{tabular}

corresponding rows again search the largest shareholder(s) in $\mathbf{P}+\mathbf{S C} \mathbf{C}^{(0)}$, and assign a positive value of control coefficients in $\mathbf{C}^{(0)}$, which after this adjustment is denoted by $\mathbf{C}^{(1)}$. Then compute $\mathbf{P}+\mathbf{S C}^{(1)}$, and the same procedure is applied until every firm is assigned to some primary owner(s). Table 6 gives the final control assignment matrix $\mathbf{C}^{\text {final }}$ and Table 7 the matrix of control rights $\mathbf{P}+\mathbf{S C}^{\text {final }}$ according to the "dominant shareholder" methodology. Note that the conditions in footnote 11 are satisfied.

In order to examine the relation between network complexity measures and the degrees of separation of $\mathrm{C}$ and $\mathrm{O}$ rights, we first note that in measuring distance focusing entirely on either $\mathbf{T}$ or WADTL (or similarly on either $\mathbf{Y}$ or WADIL) would be misleading. The drawback of only considering the matrix $\mathbf{T}$ and/or $\mathbf{Y}$ is that it does 
Table 8 Simple correlation between ownership network complexity measures and the degrees of separation (C-O) of control and dividend rights

\begin{tabular}{|c|c|c|c|c|c|c|c|}
\hline & \multicolumn{3}{|c|}{$(C-O)_{i k} \quad 156$ observations } & \multirow[t]{2}{*}{ Average } & \multicolumn{3}{|c|}{$(\bar{C}-\bar{O})_{k} \quad 13$ observations } \\
\hline & WL10 & WL20 & $D S$ & & WL10 & WL20 & $D S$ \\
\hline WADTL & 0.318 & -0.026 & -0.014 & WADTL & 0.253 & -0.284 & -0.145 \\
\hline WADTL2 & 0.315 & 0.063 & 0.059 & WADTL2 & 0.583 & 0.728 & 0.470 \\
\hline WADTL5 & 0.181 & 0.282 & 0.245 & WADTL5 & 0.548 & 0.913 & 0.746 \\
\hline WADTL10 & 0.212 & 0.358 & 0.310 & WADTL10 & 0.575 & 0.920 & 0.739 \\
\hline WADIL & 0.377 & 0.085 & -0.023 & WADIL & 0.332 & -0.126 & -0.025 \\
\hline WADIL2 & 0.479 & 0.385 & 0.050 & WADIL2 & 0.630 & 0.843 & 0.600 \\
\hline WADIL5 & 0.301 & 0.451 & 0.238 & WADIL5 & 0.524 & 0.860 & 0.731 \\
\hline WADIL10 & 0.213 & 0.357 & 0.306 & WADIL10 & 0.460 & 0.681 & 0.566 \\
\hline$D S$ & -0.070 & 0.089 & & $D S$ & 0.416 & 0.817 & \\
\hline
\end{tabular}

$C-O$ is the difference between control and ownership rights. $(C-O)_{i k}$ does so for the interests of primary owner $k(=1, \ldots, 13)$ in in each secondary owner $i(=1, \ldots, 12),(\bar{C}-\bar{O})_{k}$ takes the average over the secondary owners. $W L$ and $D S$ stand for, respectively, the "weakest link" and "dominant shareholder" approaches of identifying control rights. WL10 means that the threshold level for control rights is $10 \%$ (otherwise the corresponding cell in Table 5 is set to zero). WADTL5 (WADIL5) takes the positive values of WADTL (WADIL) if the corresponding total (indirect) ownership is at least $5 \%$

not reflect the complexity of a certain relation, since their elements do not allow to distinguish how many intermediary owners are involved in a certain link. The limitation of focusing entirely on WADTL and/or WADIL is that the size of the total and/or indirect linkages is ignored. The only issue that matters is the "distance" between a primary and a secondary owner. For example, for the case with the largest WADIL (which was graphed in Fig. 1), we have that $t_{11,6}=y_{11,6}=0.00$, which is a very negligible share. The issue thus arises whether it makes sense to consider this specific relation. To solve this problem both types of indicator are combined. That is, we take the average distance into account only if the size of the linkage is sufficiently large, using a threshold level.

Table 8 gives the simple correlations between the various indicators. Note that ownership (O) in all cases is represented by the matrix $\mathbf{T}$. First, the relation between control and ownership differences $(\mathrm{C}-\mathrm{O})$, with $\mathrm{C}$ measured by the "weakest link" (WL) and "dominant shareholder" (DS) approaches, is given in the bottom row of Table 8. The full sample takes C-O into account for every pair of primary and secondary owner (thus, $n \times m=12 \times 13=156$ observations). No significant correlation is found between the WL and the DS indicator of separation of $\mathrm{O}$ and $\mathrm{C}$. However, if the average is taken over all secondary owners (for each primary owner, which yields $m=13$ observations), positive correlations are found. Moreover, the correlations are much higher with a threshold level of $20 \%$ for the "weakest link" control rights. Hence, for the Czech banking sector, the two "standard" approaches result in approximately the same outcomes for the separation of $\mathrm{O}$ and $\mathrm{C}$ when the average control rights of the primary owner are compared, while the results differ significantly when all specific control rights are considered. 
Next, we consider the results for the case where the control rights are obtained from the distance measures WADIL and WADTL. When size is not taken into account (i.e. distance indicators are considered without any threshold), there is no clear link between the WL and DS measures of separation of $\mathrm{C}$ and $\mathrm{O}$, and the corresponding distances. However, once ownership size is taken into account (with threshold levels of 2,5 or $10 \%$ ) the WADILs and WADTLs show a positive correlation with the WL and DS measures for $\mathrm{C}$ and $\mathrm{O}$ differences, i.e. the wedge between $\mathrm{C}$ and $\mathrm{O}$ rights is greater (i.e. C-O is larger) when there is more complex network of ownership links (i.e. when WADTL and WADIL are larger).

Focusing on the cases where a threshold level is applied to the distance measures yields the following conclusions. First, the correlation is larger for average indicators (in the right panel of Table 8) than for the individual indicators (in the left panel). Second, in the full sample the correlations of C-O measures from the "weakest link" approach are on average larger when WADILs are used than when WADTLs are used, while the opposite holds for C-O measures computed by the DS approach. In the sample with $\mathrm{C}-\mathrm{O}$ measures averaged over secondary owners, the correlations are stronger for WADIL than for WADTL at the $2 \%$ threshold level, whereas the opposite holds for the 5 and $10 \%$ threshold levels. Thus, for higher threshold levels (imposed on total and indirect linkages), WADTL measures are preferred in indicating $\mathrm{C}$ and $\mathrm{O}$ gap. This is because the WADTLs take direct and indirect shareholding linkages into account and both matter in determining the control power of a primary owner.

The empirical results clearly suggest that the distance measures WADTL and WADIL can be considered as alternative measures of the degree of separation of $\mathrm{C}$ and $\mathrm{O}$ due to pyramiding structures and cross-holding. When compared to the WL and DS methodologies, using WADIL and WADTL as indicators of separation of C and $\mathrm{O}$ has several clear advantages. First, its computation is extremely simple. Second, in contrast to the WL approach and similar to the DS methodology, the notion of distance takes all possible webs of property relations due to cross-ownership into full account. Furthermore, the distances are weighted by their corresponding contributions to total and indirect links, which make them preferable to, say, the minimum distance approach used in sociology literature. Third, unlike the DS approach, there is no such notion as the multiplicity of control assignments (hence multiple control rights values). ${ }^{13}$ Consequently, every initial primary and secondary property distributions have unique WADTL and WADIL matrices. Fourth, like DS approach, WADIL and WADTL also consider the notion of "management control", when a firm is (partially) controlled by an owner without ownership in dividend rights at all. ${ }^{14}$ On the other hand, similar to the DS methodology, the distance concept has a disadvantage that it focuses on the effects of cross-shareholding and does not consider other control arrangements, like dualclass shares and voting caps. But given our observations mentioned in the beginning

\footnotetext{
13 To deal with this issue, Dorofeenko et al. (2008) introduce the notion of control "tightness" that gives the maximally stable control assignment.

14 In our empirical application this applies to significant indirect ownership of $P O 7$ in $S O 2$, or $P O 1$ in $S O 6$, SO7, and SO11 with zero direct dividend rights.
} 
of this subsection, we expect the bias from the one-share-one-vote assumption to be small. $^{15}$

\section{Conclusions}

In this paper, we have studied ownership relations between primary owners (such as individuals and the state) and secondary owners (such as companies and banks). In the presence of cross-shareholding among secondary owners, the property structure may become quite complex. Cross-shareholding is widely observed in modern economies and is an important characteristic of Japanese, German and Swedish business groups in particular. The observed property distribution reflects only direct shareholding and may be highly misleading because it hides the true property distribution. This true property distribution can only be obtained by taking also all indirect shareholding into full account. As a consequence, all property that is held by secondary owners accrues to the primary owners. The true property distribution allows for the calculation of the total property that is embedded in a $1 \%$ share in some corporation and the total property that is held by some primary owner.

For analyzing the ownership relations or linkages, two aspects are important. These are the size of the indirect or total (i.e. direct and indirect) linkages between a primary owner and a secondary owner, and the average distance of the linkages between the two. The last is obtained from the average number of secondary owners via whom the relation runs. The average distance indicates the complexity of the indirect linkages between a primary and a secondary owner and is taken into account only for the important linkages (i.e. those that are larger than a pre-specified threshold).

The methodology has been applied to the banking sector in the Czech Republic, which allowed us to get some insight into the "hidden property structures" of this sector. The complexity of the network of relations between primary and secondary owners was quantified. There is ample evidence that indirect ownership relations play a crucial role in the Czech banking sector.

Further, we found a clear link between ownership complexity measures proposed in this paper and the degree of separation of dividend and control rights, largely investigated in the finance literature. The idea is that the more complex the network of non-negligible relations is, the larger the degree of control enhancement due to cross-shareholding links among firms. Hence, the larger the difference is between the control and the ownership stakes of primary owners in secondary owners. The empirical results confirm this for the Czech banking sector.

As a final remark, it should be noted that the empirical analysis of the Czech banking sector was carried out as if it were a closed, domestic system. However, some of the primary owners are in fact secondary owners in other countries. It may thus be the case that say $20 \%$ of the property of one of the Czech investment funds accrues to a

\footnotetext{
15 Dorofeenko et al. (2008), in supporting their assumption of the absence of other control arrangements, argue that "... these other control devices will most likely reinforce the control assignment emerging from the pure one-share-one vote arrangement, as they are presumably designed by controlling shareholders".
} 
German bank, for example. This points at foreign holding of Czech property. In its turn, it is in principle possible that e.g. the Czech National Bank holds (directly and indirectly) $50 \%$ of this German bank. This would imply then that only $10 \%$ of the property of this Czech investment fund flows abroad, while $10 \%$ accrues to the Czech National Bank.

It is clear that the first part (i.e. foreign ownership of Czech property) of the example above is included in our analysis. The second part (i.e. Czech ownership of foreign property), however, is not. To do so, would at least require detailed information on shareholding in Germany. In general, if international cross-shareholding occurs, insight into the property structure and the international ownership relations would require a full interregional input-output framework (see e.g. Miller and Blair 1985 for an excellent introduction, and Dietzenbacher and Romero 2007, for an application of distance to interregional production chains). That is, the necessary information would be given by expanded initial property distribution matrices $\mathbf{P}$ and $\mathbf{S}$. Element $p_{i k}^{R U}$ would give the share in secondary owner $i$ in country $R$, that is held by primary owner $k$ in country $U$. Similarly, $s_{i j}^{R U}$ would indicate the share in secondary owner $i$ in country $R$, that is held by secondary owner $j$ in country $U$. Given the ongoing internationalization of shareholding, constructing and analyzing a full-fledged interregional database will be a major challenge for the future.

Acknowledgments We are indebted to three anonymous referees for their useful comments and suggestions. Earlier versions of this paper have been presented at the $2006 \mathrm{SOM} \mathrm{Ph} . \mathrm{D}$. Conference at the University of Groningen and the 2006 Intermediate Input-Output Meetings in Sendai (Japan).

Open Access This article is distributed under the terms of the Creative Commons Attribution Noncommercial License which permits any noncommercial use, distribution, and reproduction in any medium, provided the original author(s) and source are credited.

\section{Appendix A. The list of primary and secondary owners of the banking sector in the Czech Republic}

PO1 - Fond národního majetku (Fund of National Property), state agency

$P O 2$ - Česká národní banka (Czech National Bank), central bank

PO3 - Ministerstvo financí (Ministry of Finance), state agency

PO4 - Sdružení měst (Association of Municipalities)

PO5 - Bank Holding, non-state

PO6 - J. Ring stock company, non-state

PO7 - First Privatization Holding, non-state

PO8 - The Bank of New York

PO9 - Nomura Group

$P O 10$ - The Midland Bank

PO11 - The Bankers Trust Investment

PO12 - Slovak Republic

PO13 - minority investors

SO1 - Česká spořitelna (Czech Saving Bank)

SO2 - Česká pojišt'ovna (Czech Insurance) 
SO3 - Komerční banka (Commercial Bank)

SO4 - Invesiční a poštovní banka (Investment and Post bank)

SO5 - Československá obchodní banka (Czecho-Slovak Trade Bank)

SO6 - Spořitelní privatizační fond - Český (investment fund)

SO7 - Spořitelní privatizační fond - výnosový (investment fund)

SO8 - První privatizační fond (investment fund)

SO9 - První investiční fond (investment fund)

SO10 - Restituční investiční fond (investment fund)

SO11 - Investiční privatizační fond Komerční banky (investment fund)

SO12 - Vojenskě stavby (stock company)

Appendix B. The initial property distribution for the banking sector in the Czech Republic

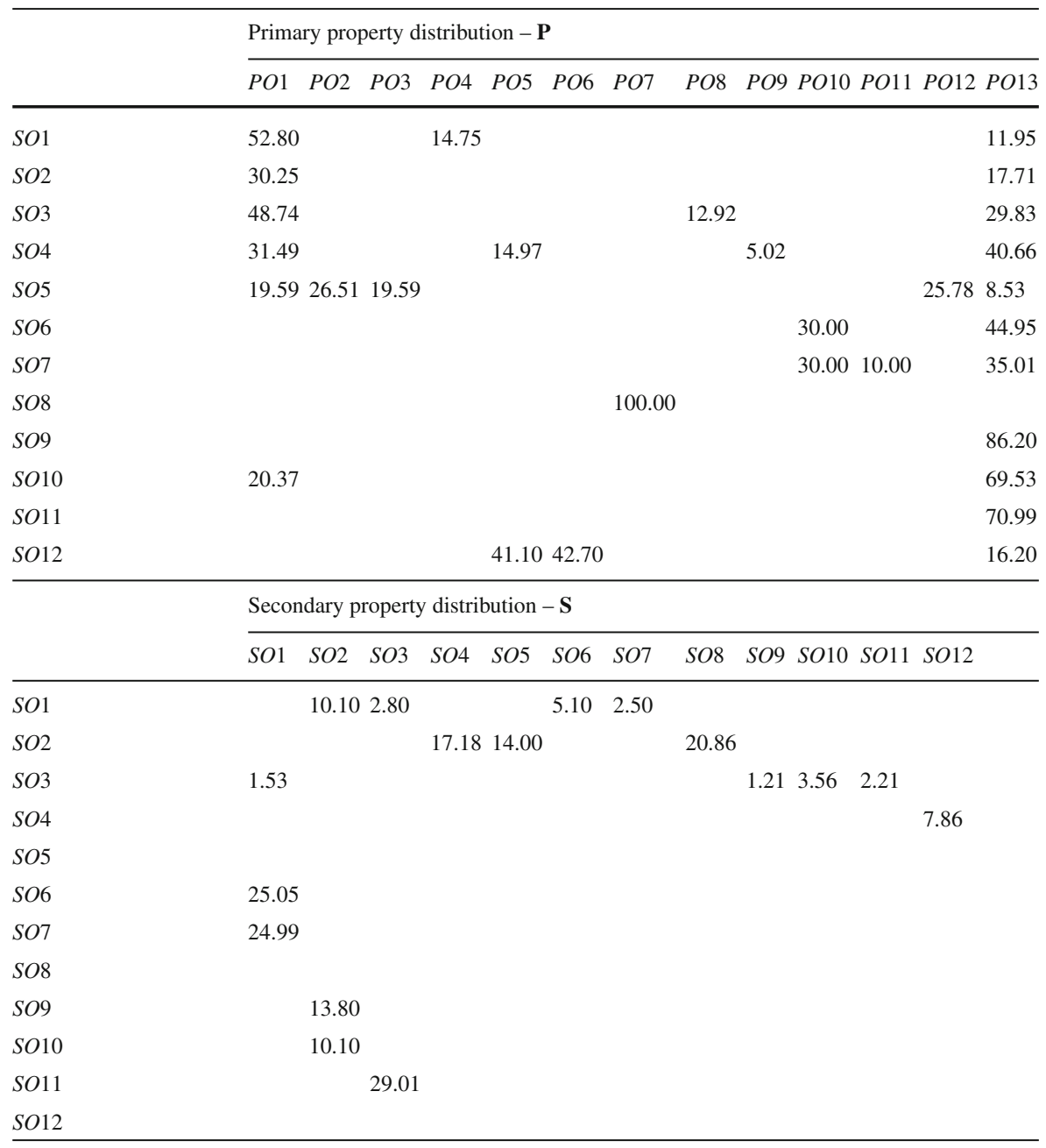

Source: Turnovec (1999) 


\section{References}

Alley WA (1997) Partial ownership arrangements and collusion in the automobile industry. J Ind Econ 45:191-205

Attig N, Gadhoum Y (2003) The Governance of Canadian Traded Firms: an Analysis of the Ultimate Ownership Structure, Available at SSRN: http://Ssrn.Com/Abstract=434160, doi:10.2139/Ssrn.434160

Bebchuk LA, Kraakman R, Triantis G (2000) Stock pyramids, cross ownership, and dual class equity:the creation and agency costs of separating control from cash flow rights. In: Morck RK (ed) Concentrated corporate ownership. University of Chicago Press, Chicago

Bolle F, Güth W (1992) Competition among mutually dependent sellers. J Inst Theor Econ 148:209-239

Bresnahan T, Salop SC (1986) Quantifying the competitive effects of production joint ventures. Int J Ind Organ 4:155-175

Claessens S, Djankov S, Lang LHP (2000) The Separation of Ownership and Control in East Asian Corporations. J Financ Econ 58:81-112

Dietzenbacher E, Romero I (2007) Production chains in an interregional framework: Identification by means of average propagation lengths. Int Reg Sci Rev 30:362-383

Dietzenbacher E, Romero I, Bosma N (2005) Using average propagation lengths to identify production chains in the Andalusian economy. Estud de Economía Apl 23:405-422

Dietzenbacher E, Smid B, Volkerink B (2000) Horizontal integration in the Dutch financial sector. Int J Ind Organ 18:1223-1242

Dorofeenko V, Lang LHP, Ritzberger K, Shorish J (2008) Who controls allianz? measuring the separation of dividend and control rights under cross-ownership among firms. Annals of Finance 4:75-103

Ellerman DP (1991) Cross ownership of corporations: a new application of input-output theory. Metroeconomica 42:33-46

Ellerman DP (1995) Intellectual trespassing as a way of life: essays in philosophy, economics, and mathematics. Rowman and Littlefield, Lanham

Faccio M, Lang LHP (2002) The ultimate ownership of Western European corporations. J Financ Econ 65:365-395

Faccio M, Lang LHP, Young L (2001) Dividends and expropriation. Am Econ Rev 91:54-78

Flath D (1989) Vertical integration by means of shareholding interlocks. Int J Ind Organ 7:369-380

Flath D (1991) When is it rational for firms to acquire silent interests in rivals? Int J Ind Organ 9:573-583

Flath D (1992a) Horizontal shareholding interlocks. Managerial Decis Econ 13:75-77

Flath D (1992b) Indirect shareholding within Japan's business groups. Econ Lett 38:223-227

Flath D (1993) Shareholding in the keiretsu, Japan's financial groups. Rev Econ Stat 75:249-257

Franks J, Mayer C (1995) Ownership and control. In: Siebert H (ed) Trends in business organization: do participation and cooperation increase competitiveness? J.C.B. Mohr, Tübingen, pp 171-195

Gadhoum Y, Lang LHP, Young L (2005) Who controls US? Euro Financ Manag 11:339-363

Gilo D, Moshe Y, Spiegel Y (2006) Partial cross ownership and tacit collusion. RAND J Econ 37:81-99

Harthoorn R (1988) On the integrity of data and methods in the static open leontief model. (Enschede, University of Twente, Faculty of Public Administration and Public Policy, Ph.D. Thesis)

Kenway P, Klvacova E (1996) The web of cross-ownership among czech financial intermediaries: an assessment. Europe-Asia Stud 48:797-809

Kester WC (1992) Industrial groups as systems of contractual governance. Oxf Rev Econ Policy 8(3):24-44

La Porta R, Lopez-de-Silanes F, Shleifer A (1999) Corporate Ownership Around the World. J Financ 54:471-517

La Porta R, Lopez-de-Silanes F, Shleifer A, Vishny R (2002) Investor protection and corporate valuation. J Financ 57:1147-1170

Lichtenberg F, Pushner G (1994) Ownership structure and corporate performance in Japan. Jpn World Econ 6:239-261

Merlone U (2001) Cartelizing effects of horizontal shareholding interlocks. Manag Decis Econ 22:333-337

Miller RE, Blair PD (1985) Input-Output analysis: foundations and extensions. Prentice-Hall, Englewood Cliffs

Morck R, Nakamura M, Shivdasani A (2000) Banks, ownership structure, and firm value in Japan. J Bus 73:539-567

Nikaido H (1968) Convex structures and economic theory. Academic Press, New York

Prowse S (1990) Institutional investment patterns and corporate financial behavior in the United States and Japan. J Financ Econ 27:43-66 
Reitman D (1994) Partial ownership arrangements and the potential for collusion. J Ind Econ 42:313-322 Reynolds RJ, Snapp BR (1986) The competitive effects of partial equity interest and joint ventures. Int J Ind Organ 4:141-153

Takayama A (1985) Mathematical economics, 2nd edn. Cambridge University Press, Cambridge

Turnovec F (1999) Privatization, ownership structure, and transparency: how to measure the true involvement of the state. Euro J Polit Econ 15:605-618

Turnovec F (2005) Arithmetics of property rights: a Leontief-type model of ownership structures. Homo Oeconomicus 22:371-379

Weinstein D, Yafeh Y (1995) Japan's corporate groups: collusive or competitive? an empirical investigation of Keiretsu behavior. J Ind Econ 43:359-376

Weinstein D, Yafeh Y (1998) On the costs of a bank-centered financial system: evidence from the changing main-bank relations in Japan. J Financ 53:635-672

Yafeh Y, Yosha O (2003) Large shareholder and banks: who monitors and how? Econ J 113:128-146

Yan CS, Ames E (1965) Economic interrelatedness. Rev Econ Stud 32:299-310 